\title{
Self-Esteem and Tendency of Bullying among Primary School Children
}

\author{
Chin-Siang Ang ${ }^{1 *}$, Chien-Ping Chong ${ }^{2}$, Shuet-Wen Cheong ${ }^{2}$, Chiew-Yen Lee ${ }^{2}$, ZhenHui Tang ${ }^{2}$ \& \\ Chooi Yen Liew ${ }^{2}$ \\ ${ }^{1}$ School of Psychology, TMC Academy, Singapore. \\ ${ }^{2}$ Department of Psychology, Faculty of Social Sciences and Liberal Arts, UCSI University, Kuala Lumpur, Malaysia.
}

Received 22.03.2018; Received revised 07.06.2018; Accepted 22.06.2018

Available online 30.06 .2018

\begin{abstract}
In this exploratory research, a mixed method research design was used to understand how primary school children perceive bullying behaviour and to uncover the extent of self-esteem on their bullying experiences. Two hundred and eighty participants took part in a survey of their bullying behaviour and self-esteem. Additionally, semi-structured interviews were conducted with 6 children. Survey findings indicated that higher self-esteem leads to higher bullying behaviour. Further analyses within sub-samples defined by gender and ethnic subgroups revealed that there are differences in bullying behaviour across subgroups. In addition, qualitative interviews yielded three key themes including (i) physical and verbal bullying, (ii) relational bullying, and (iii) gender-based bullying.
\end{abstract}

Keywords: bullying, mixed-method, primary school children, self-esteem.

Address of correspondence: Ang Chin-Siang, School of Psychology, TMC Academy, 250

Middle Road, 188983, Singapore.

E-mail: austin.ang@tmc.edu.sg

\section{Introduction}

Bullying, a form of behavioural aggression, is a widespread phenomenon which can happened anywhere (Jeong, Kwak, Moon, \& Miguel, 2013). Among different age-based bullying, child bullying has garnered the most research attention. It is defined as when a child intends to harm someone who they think as weaker than themselves (Smokowski \& Kopasz, 2005). Child bullying is a growing hazard worldwide. According to Smokowski and Kopasz (2005), one in three school-going children in the United States were the victims of bullying. Few scholarly works continually identified such problem still persists and is in a rising trend (Karatas \& Ozturk, 2011, Ttofi, Farington, \& Losel, 2012, Wang, Iannotti \& Nansel, 2009). However, bullying behaviours are not only evident in Western contexts, but are also found in Asian societies (Wang et al., 2009; Wan Ismail, Jaafar, Sidi, Midin, \& Shah, 2014; Yang, Kim, Kim, Shin \& Yoon, 2006). Wan Ismail et al.'s (2014) study reported 8 out of 10 school children in Malaysia experience some forms of bullying.

Bullying behaviours are categorized into three broad domains: physical bullying, verbal bullying, and relational bullying (Ando, Asakura, \& Simons Morton, 2005; Wang et al., 2009). Physical bullying refers to an overt act of inflicting physical harm upon a person (e.g., kicking and fighting); verbal bullying refers to a direct attempt of verbally attack someone (e.g., teasing and insulting); relational bullying is a type of covert aggression in which bullying is caused by social exclusion. In subsequent years, Karen (2012) proposed a four taxonomic-structure of bullying behaviour: physical bullying, verbal bullying, sexual bullying and cyber bullying, and found each 3 out of 10 children experience at least one type of bullying. This has come about because of rapid progress in technology which could be much more difficult to identify and control (Weiten, Hammer, \& Dunn, 2012). As shown, bullying is negatively affect one's physical, social, and emotional well-being (Bradshaw, Sawyer, \& O’Brennan, 2009; Patchin \& Hinduja, 2010; Sigurdson, Wallander, \& Sund, 2014). Specifically, victims of bullying are more susceptible to mental illnesses and poor school performance (Nansel, Overpeck, Pilla, Ruan, Simons, \& Scheidt, 2001), whereas bullies are more likely to report externalizing problems (Sigurdson et al., 2014).

Throughout the years, literature has identified risk factors of engaging bullying behaviour. Few common key factors are poor self-control (Wang et al., 2009), low selfesteem (Bushman, Baumeister, Thomaes, Ryu, Begeer \& West, 2009), psychological disturbance (Nansel et al., 
2001), and family disruption (Jeong et al., 2013). While most risk factors are consistently explained bullying behaviour, the influence of self-esteem remains controversial. In some studies, self-esteem was not correlated with bullying behaviour (Chen \& Wei, 2011; Seals \& Young, 2003; Thomaes, Bushman, Stegge \& Olthof, 2008; Tritt \& Duncan, 1997). However, there are a number of studies reported self-esteem is related to bullying behaviour in either positive (Koh \& Wong, 2015; Menon, Tobin, Corby, Menon, Hodges, \& Perry, 2007; Salmivalli, 2010; Slee \& Rigby, 1993; Volk, Camilleri, Dane, \& Marini, 2012; Yang, Kim, Kim, Shin \& Yoon, 2006) or negative direction (Donnellan et al., 2005; Özdemir, 2014; Patchin \& Hinduja, 2010; Skues, Cunningham \& Pokharel, 2005).

While self-esteem is evidently important to everyone in different ways, the irony is that high levels of self-esteem can cause externalizing problems (Koh \& Wang, 2008). With the possible positive effects to psychological health, why do some psychologists believe self-esteem is detrimental? Though counter-intuitive, self-esteem is not all good. In a psychological context, self-esteem is a person's general subjective perception of his or her own worth (Engler, 2013). It is key for survival that can acts as an impetus that motivates us to achieve a goal. And in response to this need, self-esteem may inherently include the trait of aggression in an attempt to get better self-worth (Bandura, 1973).

In addition, empirical evidence showed that bullying behaviour is found to be more common in boys than in girls (Liang, Flisher \& Lombard, 2007; Nansel et al., 2001; Pepler, Craig, Connolly, Yuile, McMaster \& Jiang, 2006). A review paper also reported on studies where boys outnumber girls in every kind of aggressive behaviours (Berger, 2007). In a cross-national study that involves 40 countries, gender differences in bullying behaviour was also reported, which boys reported higher rates of aggressive behaviour in all studied countries (Craig et al., 2009). While boys often engage in physical assaults and teasing, girls are more likely to exhibit what has been termed relational aggression, such as active exclusion from a social group (Hadley, 2003). Deriving from earlier studies, more boys than girls reported having higher tendency of bullying, mainly due to two main reasons, (I) boys' direct bullying (e.g., physical assaults) is always easier to detect, while, girls' indirect bullying (e.g., relational bullying) is more difficult to notice by others. Furthermore, boys are always coined with the term "playful, impulsive, and aggressive" (Silva, Pereira, Mendonça, Nunes, \& Oliveira, 2013), which lead them more likely to be bullies compared to females. Notwithstanding this, significant differences of bullying behaviours across different cultures and ethnic groups were found in few studies (Bradshaw, Sawyer \& O'Brennan, 2009; Fox \& Stallworth, 2005; Pomeroy, 2013). All these studies unanimously reported that majority ethnic group will more likely to behave aggressively or engage in bullying as a mean of achieving social dominance in the societies.

Since the relationship between self-esteem and bullying behaviour is grey, the aims of this study were to assess tendency of bullying and its relationship with selfesteem, as well as to explore its difference between genders and ethnics. Also, a review of the relevant studies in this research scope revealed that there is lack of empirical studies investigating bullying behaviours among Malaysian students (Wan Ismail et al., 2014), and more specifically, of primary school students. Therefore, this research study aims to examine the phenomenon of child bullying behaviour among Malaysian school-age children and its relationship to self-esteem using a mixed-method approach. Overall, there are two research objectives in this study: (1) to examine if there is a significant relationship between child bullying behaviour and self-esteem among Malaysia school-age children, as well as if the bullying behaviours are subject to gender and ethnic differences; (2) to examine the type of bullying experiences Malaysia school age children have undergone.

\section{Method}

\section{Research Design}

A mixed-method approach was used in this study to address all research questions. This study adopted pragmatism which combines both positivist and interpretive positions to look at a single research scope in depth (Gelo, Braakmann, \& Benetka, 2008). To increase validity of the study findings, triangulation method was used to collect and analyze qualitative and qualitative data simultaneously to provide a better understanding of the research problem than either one type by itself (Creswell \& Garrett, 2008).

\section{Participants}

To address the first research objective of this study, a total of 280 primary school students $(M=10.67, S D=$ 1.27 ; age ranges $=7-12$ ) were recruited in federal territories of Malaysia. The sampling was a convenience design with a total of 10 primary schools selected according to districts in the state. For each sampled school, one to two classes' students were invited to participate in the survey to avoid interruption of school learning time as emphasized by the school principals. Of the collected samples, $38.2 \%(\mathrm{~N}=107)$ were males and $61.8 \%(\mathrm{~N}=$ 173) were females. As for ethnic distribution, $60 \%(\mathrm{~N}=$ 168) were Malay, $18.6 \%(\mathrm{~N}=52)$ were Chinese, $16.8 \%(\mathrm{~N}$ $=47)$ were Indian, and the remaining $4.6 \%(\mathrm{~N}=13)$ were of indigenous people. At the same time, semi-structured interviews on the primary school children were conducted to qualitatively explore the type of bullying experiences Malaysia school age children have undergone. Of the qualitative sample, we approached the same group of participants via Extreme Case Sampling (Creswell, 1998). However, only six children were voluntarily joined the interviews, together with the parents' consent.

\section{Instruments}

As abovementioned, both quantitative and qualitative instruments were integrated in this study. For the quantitative instruments, two established scales were included in this study:

Self-esteem. The majority of self-esteem research has focused on global self-esteem measures (Kususanto, Ismail \& Jamil, 2010; Robins, Hendin \& Trzesniewski. 2001). One global self-esteem measure is Robins et al.'s (2001) Self-Esteem Scale. The scale takes a broad view of the self-esteem concept and requires participants to make an overall assessment about their self-worth and that are not related to specific domains or areas. This global, onedimensional measure of one's self-esteem contains a single item (i.e., I have high self-esteem). To respond, participants selected one of seven response keys - not very true of me to very true of me-to indicate the extent of 
their self-esteem. Prior studies showed this single-item scale had similar predictive validity and convergent validity with Rosenberg's Self-Esteem Scale (Robins et al., 2001).

Bullying behaviour. Orpinas and Frankowski's (2001) Aggression Scale was used to measure tendency of bullying of the participants. In the research literature, the term aggressive behaviour and bullying behaviour are almost synonymous (Hwang, Kim, Koh, Bishop, \& Leventhal, 2017; Reynolds \& Kamphaus, 2015; Sattler \& Hoge, 2014). It consists of physical or verbal behaviours that threaten or harm others. The scale measures individual self-reported on physical and verbal bullying behaviours upon others in the past seven days. an 11-item scale. Higher scores indicate that the participants are more likely to engage in bullying behaviours. Prior studies showed this scale had high reliability and construct validity (Orpinas \& Frankowski, 2001). Some sample items include 'I pushed shoved other students,' I called other students bad names,' 'I threatened to hurt or to hit someone.' The scale reliability of this study was .85 .

For the qualitative instrument, researchers served as research tools. Throughout the course of the research project, the research team employed a reflexive process to analyse individual team members' understandings, assumptions, and biases, with regard to self-esteem and bullying behaviour. Such process can lessen the effect of individual team members' biases in developing project goals, research questions, and interpretation of the interviewees' narratives.

\section{Procedure}

Formal approval of authority from each school involved was sought prior to the sample recruitment and data collection. During the day of data collection, the nature of the study and objectives were explained to the potential participants in selected classrooms and they were required to sign informed consent forms to indicate their willingness to join this research. The participants were then asked to complete the questionnaire within the stipulated time frame. The questionnaire was collected on the spot to increase response rates. To get a detailed investigation of students' views and bullying experiences, semi-structured interviews were concurrently conducted. During the interview sessions, respondents were presented with a list of open-ended questions. Probing questions were also asked to clarify any vague statement from the participants. Permission for interview records was sought from the participants and their guardians, and data transcription were also made available to them to comment (von Manen, 1990). This ensures accuracy of data analysis and interpretation to achieve the methodological rigor. To avoid researcher bias, bracketing of presuppositions was carried out throughout the study on understanding participants' descriptions (Giorgi, 1994). Confidentiality of participants' data was ensured and pseudonyms were adopted in data reporting.

\section{Data analysis}

Quantitative data in this study were analysed via the Statistic Package for Social Science (SPSS). Pearson correlation coefficient, t-test and one way-ANOVA were used. For the qualitative data, analyses were employed based on von Manen (1990)'s analytic procedures. Emerging themes were coded into categories, re-evaluated and re-interpreted into shifting codes until the final themes emerged.

\section{Results}

Descriptive statistics and correlations

Table 1 presents descriptive statistics and correlation between the study variables. The mean of bullying and self-esteem was $28.18(S D=13.18)$ and $3.63(S D=1.50)$ respectively. In addition, there was a significant relationship between self-esteem and child bullying behaviour among Malaysia school-age children $(r=.35, p$ $<.001)$. Self-esteem was moderately and positively related to children's bullying behaviour. Indicatively, as the level of self-esteem increases, bullying behaviour increases as well.

Table 1. Descriptive statistics and correlations

\begin{tabular}{lll}
\hline Variable & 1 & 2 \\
\hline 1. Bullying & - & \\
2. Self-esteem & $.35^{*}$ & - \\
$M$ & 28.18 & 3.63 \\
$S D$ & 13.18 & 1.50 \\
\hline
\end{tabular}

Note: $M=$ Mean, $S D=$ Standard deviation, $* p<.001$.

Gender and ethnic differences on bullying behaviour

Independent Sample t-test showed that there was a significant difference between boys and girls on bullying behaviour $(t(249)=4.74, p<.001)$. In particular, boys $(M$ $=32.61, S D=11.57)$ scored higher on bullying behaviour than girls $(M=25.43, S D=13.39)$ (see Table 2$)$.

Table 2. Gender differences on bullying behaviour

\begin{tabular}{|c|c|c|c|c|}
\hline & $M$ & $S D$ & $t$ & $d f$ \\
\hline Bullying & & & $4.74 *$ & 249 \\
\hline Male & 32.61 & 11.57 & & \\
\hline Female & 25.43 & 13.39 & & \\
\hline
\end{tabular}

One-way ANOVA showed that there was a significant difference between three ethnic groups on bullying behaviour $(F(2,264)=5.44, p<.01)$. Post-hoc analyses with Tukey method were further computed to compare three ethnic groups. In particular, Malay students $(M=$ $29.88, S D=11.89)$ scored significantly higher on bullying behaviour than Indian students $(M=23.10, S D=13.84)$ (see Tables 3 and 4).

Table 3. Ethnic differences on bullying behaviour

\begin{tabular}{lllll}
\hline & $M$ & $S D$ & $F$ & $d f$ \\
\hline Bullying & & & $5.44^{*}$ & 2,264 \\
Malay & 29.88 & 11.89 & & \\
Chinese & 26.79 & 14.74 & & \\
Indian & 23.10 & 13.84 & & \\
\hline
\end{tabular}

Note: $M=$ Mean, $S D=$ Standard deviation, $* p<.01$. 
Table 4. Post hoc analysis

\begin{tabular}{lll}
\hline Ethnic & Ethnic & Mean Difference \\
\hline Malay & Chinese & 3.09 \\
Malay & India & $6.77^{*}$ \\
Chinese & India & 3.68 \\
\hline Note: ${ }^{*} p<.05$. & &
\end{tabular}

Qualitative results

In particular, six participants were recruited during the qualitative phase. Four participants were boys and two participants were girls. Due to the nature of the adopted sampling, some participants were the victims of bullying and some were bullies. Three main themes emerged from the analysis of face-to-face interviews: "What were the bullying experiences that you have undergone in school?"

Theme 1: Physical and Verbal Bullying

Three participants mentioned some instances of bullying behaviour that they witnessed or experienced in classes. All the instances that they described were a form of overt bullying.

Angie, who is 11 years old, expressed her experiences about bullying: When I talked to him [the bully], he will spit his saliva toward me. Sometimes, I saw he threw paper to other victims. I could not help or do anything. If I did, I would probably in trouble. Some bullies even worse. They simply hit others and stole other people's stuff for no reason. My pens were stolen few times before. I told to my mother and she asked to me talk to the teacher. Angel, 9 years old, indicated her experiences of bullying as follow: He [the bully] is very fierce and likes to scold and punch others randomly. He talks very loud to others. Sometimes, he did the same thing to the teachers. He's just rude and mean. There are few times, he said Jarred [someone random in class] likes Barina [Angel's Best Friend]. It is not true, and he just simply say things about Barina to make other students laugh. When he saw Barina cried, he will feel happy. Jasper, 8 years old, shared his witnesses as follow: The big boy slapped my good friend. He looks tall and strong. My friend is much smaller size than him.

Some participants who were a bully described how they bullied her classmates. John, 11 years old, indicated as follow: I scolded her and asked her to go away. If she doesn't, I will push her away. I don't like her and I got angry easily with her. She is too annoying and non-stopped bugging at me. Jam, 12 years old, shared his experience as follow: Who asked him to make me angry? I pulled him and kicked him. Other students asked him to fight back, but he didn't dare. He is just lame to me. Jack, 9 years old, indicated his view as follow: I screamed at her as she is too busy body. But she went to talk to the teacher. My teacher scolded me back. I called her bad names in classroom to make her angry.

Theme 2: Relational Bullying

Participants agreed that peer rejection was seen probably as a sign of bullying. This theme arises from the circumstances of when one is being isolated or avoided by an individual or a group in schools, hence the child is being rejected or disliked by the school mates. Participants described how victims in their classrooms or schools did not receive social interaction and support from their social surroundings. Some instances of their views of relational bullying are:

Angie stated: She (a victim in her school) didn't have any friend in school. No one is willing to join her. Sam [a boy in her class] is alone too, no one wants to play with him and lend him a stationary. There is no way I could help Sam, otherwise my 'gang' [group of best friends] will boycott me. They seem pity and I feel so sad for them. Despite not personally acknowledging her bullying behaviour, Angel mentioned: I dislike her. She is very dirty and lazy. I don't let her come over my place. All of us don't want play with this 'smelly' person. We would welcome anyone who wants to join us. But you know, we can't stand her smell. Jasper mentioned: I don't have many friends. I can't 'click' with boys. Girls will talk to each other but not with me. Jam believes that there is a power of social exclusion to threat someone that he doesn't like: Very simple [giggle]. I asked my friends don't friend with Ken [a person he doesn't like]. Girls [his friends] will usually follow what I'm said, but boys don't.

Theme 3: Gender-Based Bullying

Evolving from Theme 1 and Theme 2, analyses indicate that there are differences in bullying behaviour for school boys and girls. For boys, bullying is mostly associated physical and verbal aggression, and girls were more likely to engage in relational bullying. This can be proved in some participants' transcripts:

Angie mentioned her victimization experience: Boys always punch or knock me. Girls don't friend with me. I don't with them. I am alone all times. Jam cited similar to that of Angie: my friends [boys] and I pull and kick each other while playing. We will stop when the teacher comes. Girls are quite childish. They always say don't want to friends with me if I make them angry. Angel mentioned that boys in my classroom always bullied at a fat boy by teasing him as a pig. No idea why they do so. If I don't like a person, I will ask my friend not play with her.

\section{Discussion}

This study had two-fold objectives (1) to identify if there is a significant relationship between child bullying behaviour and self-esteem among Malaysia school age children, and to establish if bullying behaviour is subjected to gender and ethnic differences, and (2) to determine the type of bullying experiences which school age children underwent. Contrary to other studies where high selfesteem was related to low aggressive tendencies or bullying (Donnellan et al., 2005; Özdemir, 2014; Patchin \& Hinduja, 2010; Skues et al., 2005), the results from the study indicate the higher the level of self-esteem, the higher the level of tendency of bullying displays. This is similar to a few published study, which found that many bullies had higher levels of self-esteem and social success compared to victims (Koh \& Wong, 2015; Menon et al., 2007; Salmivalli, 2010; Slee \& Rigby, 1993; Volk et al., 2012).

Current findings can be explained throughout the fact that the tendency to bully may be an evolutionary adaptation hard-wired trait. Although bullying has been the catchphrase of researchers for years, it is increasingly recognized that bullying is a complex problem that is not as simple as it is often portrayed. Because of the predominantly negative connotations associated with aggression/ bullying behavior, literature has focused 
mostly on the risk factors of engaging it. Conventional wisdom has repeatedly viewed bullying as the result of maladaptive development (e.g., home violence), social learning (e.g., imitation and modelling), and psychological disturbances (e.g., low self-esteem and self-loathing) (Laslett, 1980; Smokowsi \& Kopasz, 2005; Walden \& Beran, 2010). However, it is not always the case.

Bullying is a specific type of aggression in school that involves behaviours can inflict harm in the form of physical, psychological, and social to a weaker individual (Bushman et al., 2009). The evolutionary view of aggression projects that people are known to have an innate likelihood to be aggressive to safeguard survival (Bushman $\&$ Anderson, 2002). Human aggression has historically had instrument purposes to maximize lifetime reproductive success (Campbell \& Muncer, 1987). Bullying may thus be one of those inherent, adaptive traits that lead children to get social benefits and power in school (Bandura, 1973). The findings may reinforce the view of bullying is in fact a survival mechanism. Cognitive theories may further lend credence for the current findings (Archer, 2004). During early adolescence, children's brains are not fully formed, especially the part of frontal cortex, where responsible for executive functioning skills is still being developed. Children who have more tendencies to express aggression and dominance may not realize the harm they are causing when they bully, and do not take bullying as seriously as they should (Volk et al., 2012).

Similar to most previous research studies, current study also showed that boys were more likely to engage in bullying behaviours than girls (Liang et al., 2007; Nansel et al., 2001; Pepler et al., 2006). The findings support typical gender stereotypes, which argued boys are more playful, impulsive, and aggressive, whereas girls are more passive, quiet, and diplomatic (Silva et al., 2013). In addition, a significant difference of child bullying among ethnic groups was reported in the present study. Post-hoc analyses revealed that Malay students were more likely to engage in child bullying than Indian students. According to Index Mundi (2015), Malays remain as the majority ethnic group and Indian remain as the minority ethnic group. As what we've found in some past studies, a majority ethnic group tends to become bullies and a minority ethnic group was less likely to display bullying behaviours (Bradshaw et al., 2009; Fox \& Stallworth, 2005; Pomeroy, 2013). This is because a majority ethnic group may always be afraid of being challenged in their social dominance, and therefore, people in the group will more likely to behave aggressively in order to maintain their social hierarchy.

Notwithstanding this, the qualitative data was further analyzed to explain the phenomenon of child bullying. As expected, bullying behaviours in schools always involve physical and verbal bullying (Ando et al., 2005). The typical behaviours of physical bullying include kicking, hitting, beating, throwing paper, and stealing personal belonging, whereas the typical practices of verbal bullying include using abusive language, mocking, and teasing. These findings reaffirmed the conclusions of Wang et al. (2009) who argued children would more likely to experience physical and verbal bullying behaviours in schools. Besides, relational bullying or peer rejection is another form of bullying behaviour. It is a negative social experience in schools which can lead a child to feel loneliness and emptiness (Buhs, 2006; Jeong et al., 2013). Some school age children were found to socially reject victims of bullying from their social circles. The bullies may rationalize their bullying using excuses like laziness and dirtiness to label the victims of bullying in order to authenticate their bullying behaviours (Buhs, 2006; Salmivalli, 2010).

Additionally, gender-based bullying was also found. Relational bullying is considered as a female-type bullying, whereas physical and verbal bullying are considered as a male-type bullying. An explanation for the gender discrepancy in bullying behaviour may be attributed to the fact men have been conditioned as having aggressive, competitive, and impulsive traits, and in turn, they are more likely to report being hit, shoved, or punched (Wan Ismail et al., 2014). Girls, who possess softer personality traits, are more likely to use more indirect forms of bullying such as spreading gossip or social isolation (Wang et al., 2009).

This study had several practical contributions. First, the paper furthers our understanding of the relationship between bullying behaviour and self-esteem. The study revealed that higher self-esteem could lead to more bullying behaviours. One of the potential explanations is that people with high self-esteem always prioritize their personal needs and tend to have higher desire of control and defensive mechanisms (Engler, 2013). In terms of practical implication, the anti-bullying programs may consider to have supervised activity sessions in school that allow children to positively channel their aggressive traits and build their self-esteem in a friendly competitive environment. Furthermore, the differences of gender and ethnic groups should take into account when implementing prevention bullying campaign, as the bullying patterns were subjected to the gender differences and ethic differences.

\section{Conclusions}

This study employed a mixed-method approach to explain the phenomenon of child bullying in school settings. It has been found out that high self-esteem can lead to bullying behaviours among children samples. Although both genders were found to be involved in bully behaviours, males still have higher tendency than females in bully behaviours. More specifically, males were found to be more likely to use physical and verbal bullying whereas females more likely to use relational bullying. Plus, the majority ethnic group was more likely to engage in bullying behaviours compared to minority groups. Although this study provides an insights into many people's myopic perception of self-esteem and its influence, participants in this study were limited in the age ranges of 7 and 12 years old and with a relatively small sample. Also, the nature of this research was crosssectional, which data were obtained in a single occasion. In order to improve the current study, future research studies can replicate this study by extending to bigger geographical areas and other age groups, together with a larger sample size.

\section{References}

Ando, M., Asakura, T., Simons Morton, B. (2005). Psychosocial influences on physical, verbal and indirect bullying among Japanese early adolescents. The Journal of Adolescence, 25(3), 268-297. doi: $10.1177 / 0272431605276933$

Anderson, C. A., \& Bushman, B. J. (2002). Human aggression. Annual Review of Psychology, 53(1), 27-51. doi: https://doi.org/10.1146/annurev.psych.53.100901.135231 
Archer, J. (2004). Sex differences in aggression in real-world settings: A meta-analytic review. Review of General Psychology, 8(4), 291-322.

Bandura, A. (1973). Psychological mechanisms of aggression. In R. G. Green \& E. I. Donnestein (Eds.), Aggression: Theoretical and empirical views (Vol. 1, pp. 1-40). New York, NY: Academic Press.

Berger, K. S. (2007). Update on bullying at school: Science forgotten? Developmental Review, 27, 90-126. doi: 10.1016/j.dr.2006.08.002

Bradshaw, C. P., Sawyer, A. L., \& O’ Brennan, L. M. (2009). A social disorganization perspective on bullying-related attitudes and behaviours: The influence of school context. American Journal of Community Psychology, 43(3-4), 204-220. doi: 10.1007/s10464-009-9240-1

Buhs, E. S. (2006). Peer exclusion and victimization: Processes that mediate the relation. Journal of Educational Psychology, 1, 1-13. doi: 10.1037/0022-0663.98.1.1

Bushman, B. J., Baumeister, R. F., Thomaes, S., Ryu, E., Begeer, S., \& West, S. G. (2009). Looking again, and harder, for a link between low self-esteem and aggression. Journal of Personality, 77(2), 427-46. doi: 10.1111/j.1467-6494.2008.00553.x

Chen, J. K. \& Wei, H. S. (2011). The impact of school violence on self-esteem and depression among Taiwanese junior high school students. Social Indicators Research, 100(3), 479-498. doi: 10.1007/s11205-010-9625-4

Craig, W., Harel-FisH, Y., Fogel-Grinvald, H., Dostaler, S., Hetland, J., Simons-Morton, B., Molcho, M., Mato, M. G., Overpeck, M., Due., P., Picker, W., HBSC Voilence \& Injuries Prevention Focus Group, \& HBSC Bullying Writing Group (2009). A cross-national profile of bullying and victimization among adolescents in 40 countries. International Journal of Public Health, 54, 216-224. doi: 10.1007/s00038-009-5413-9

Creswell, J. W. (1998). Qualitative inquiry and research design: Choosing among five traditions. Thousand Oaks, CA: Sage Publications.

Creswell, J.W. \& Garrett, A.L. (2008). The "movement" of mixed methods research and the role of educators. South African Journal of Education, 28, 321-333.

Donnellan, M. B., Trzesniewski, K. H., Robins, R. W., Moffitt, T. E., Caspi, A. (2005). Low self-esteem is related to aggression, antisocial behaviour, and delinquency. American Psychological Society, 16(4), 328-335. doi 10.1111/j.0956-7976.2005.01535.x

Engler, B. (2013). Personality theories. Canada, CA: Wadsworth Cengage Learning.

Fox, S., \& Stallworth, L. E. (2005). Racial/ethnic bullying: Exploring links between bullying and racism in the US workplace. Journal of Vocational Behaviour, 66(3), 438456. doi:10.1016/j.jvb.2004.01.002

Gelo, O., Braakmann, D. \& Benetka, G. (2008). Quantitative and qualitative research: Beyond the debate. Integrative Psychological \& Behavioural Science, 42(3), 266-90.

Giorgi, A. (1994) A phenomenological perspective on certain qualitative research methods. Journal of Phenomenological Psychology, 25(2), 190-220.

Hadley M. (2003). Relational, indirect, adaptive, or just mean: Recent work on aggression in adolescent girls-Part I. Studies in Gender and Sexuality, 4, 367-394. doi: 10.1002/ab.21707

Hwang, S., Kim, Y. S., Koh, Y.-J., Bishop, S., \& Leventhal, B. L. (2017). Discrepancy in perception of bullying experiences and later internalizing and externalizing behaviour: A prospective study. Aggressive Behaviour, 43(5), 4930592

Index mundi. (2015). Malaysia demographics profile 2014. Retrieved from http://www.indexmundi.com/malaysia/demographics_prof ile.html
Ivarsson, T., Broberg, A. G., Arvidsson, T., \& Gillberg, C. (2005). Bullying in adolescence: Psychiatric problems in victims and bullies as measured by the youth self-report and the depression self-rating scale. Nordic Journal of Psychiatry, 59, 363-373. doi 10.1080/08039480500227816.

Jeong, S., Kwak, D. H., Moon, B., \& San Miguel, C. S. (2013). Predicting school bullying victimization: Focusing on individual and school environmental/ security factors. Journal of Criminology, 2013, 1-13. doi:10.1155/2013/401301

Karatas, H., \& Ozturk, C. (2011). Relationship between bullying and health problems in primary school children. Asian Nursing Research, 5(2), 2011, 81-87. doi: 0.101/S1976-1317(11)60016-9

Karen, I. T. (2012). Different types of bullying. Retrieved from http://www.studymode.com/essays/Different-Types-OfBullying-1287497.html

Koh, J.-B., \& Wong, J. S. (2015). Survival of the fittest and the sexiest: Evolutionary origins of adolescent bullying. Journal of Interpersonal Violence. doi: $10.1177 / 0886260515593546$.

Kususanto, P., Ismail, H. N., Jamil, I. Student's self-esteem and their perception of teacher behaviour: A study of between-class ability grouping. Electronic Journal of Research in Educational Psychology, 8(2), 707-724.

Liang, H., Flisher A. J., \& Lombard CJ. (2007). Bullying, violence, and risk behaviour in South African school students. Child Abuse \& Neglect, 31(2), 161-71. doi: 10.1016/j.chiabu.2006.08.007

Lodico, M. G., Spaulding, D. T., \& Voegtle, K. H. (2010). Methods in educational research: From theory to practice (2nd ed.). San Francisco, CA: Jossey-Bass.

Menon, M., Tobin, D. D., Corby, B. C., Menon, M., Hodges, E. V. E., \& Perry, D. G. (2007). The development costs of high self-esteem for antisocial children. Child Development, 78(6), 1627-1639. doi:10.1111/j.14678624.2007.01089.x

Nansel, T. R., Overpeck, M., Pilla, R. S., Ruan, W. J., SimonsMorton, B., \& Scheidt, P. (2001). Bullying behaviour among U.S. youth: Prevalence and association with psychosocial adjustment. Journal of the American Medical Association, 285, 2094-2100.

Orpinas, P., Frankowski, R. (2001). The aggression scale: A self-report measure of aggressive behaviour for young adolescents. The Journal of Early Adolescence, 21(1), 5067. doi: 10.1177/0272431601021001003

Özdemir, Y. (2014). Cyber victimization and adolescent selfesteem: The role of communication with parents. Asian Journal of Social Psychology, 17(4), 255-263. doi:10.1111/ajsp.12070

Patchin, J. W. \& Hinduja, S. (2010). Cyberbullying and selfesteem. Journal of School Health, 80(12), 614-621. doi: 10.1111/j.1746-1561.2010.00548.x.

Pepler, D. J., Craig, W. M., Connolly, J. A., Yuile, A., McMaster, L., \& Jiang, D. (2006). A developmental perspective on bullying. Aggressive Behaviour, 32, $376-$ 384. doi: $10.1002 / \mathrm{ab} .20136$

Polit, D. F., \& Beck, C. T. (2008). Nursing research: Generating and assessing evidence for nursing practice (8th ed.). New York: Lippincott Williams \& Wilkins.

Pomeroy, E. C. (2012). The bully at work: What social workers can do? Social Work, 58(1), 58. doi:10.1093/sw/sws055

Reynolds, C. R. \& Kamphaus, R. W. (2015). Behaviour assessment system for children (3rd ed.). Bloomington, MN: Pearson Assessments.

Robins, R. W., Hendin, H. M., \&Trzesniewski, K. H. (2001). Measuring global self-esteem: Construct validation of a single-item measure and the Rosenberg Self-Esteem Scale. Personality and Social Psychology Bulletin, 27, 151-161. 
Rosenberg, M. (1965). Society and the adolescent self-image. Princeton, NJ: Princeton. University Press.

Salmivalli, C. (2010). Bullying and the peer group: A review. Aggression and Violent Behaviour, 1, 112-120. doi:10.1016/j.avb.2009.08.007

Sattler, J. M., \& Hoge, R. D. (2014). Assessment of children: Behavioural, social and clinical foundations. (5th ed.). San Diego, California: Jerome M Sattler Publishing.

Seals, D. \& Young, J. (2003). Bully and victimization: Prevalence and relationship to gender, grade level, ethnicity, self-esteem, and depression. Adolescence, 38(152), 735-47.

Sigurdson, J. F., Wallander, J., \& Sund, A. M. (2014). Is involvement in school bullying associated with general health and psychosocial adjustment outcomes in adulthood? Child Abuse \& Neglect, 38(10), 1607-1617. doi:10.1016/j.chiabu.2014.06.001

Silva, M. A.I,. Pereira, B., Mendonça, D., Nunes, B., \& Oliveira, W. A. D. (2013). The involvement of girls and boys with bullying: An analysis of gender differences. International Journal of Environmental Research of Public Health, 10(12), 6820-6831, doi 10.3390/ijerph 10126820

Skues, J., Cunningham, E., \& Pokharel, T. (2005). The influence of bullying behaviours on sense of school connectedness, motivation and self-esteem. Australian Journal of Guidance and Counselling, 15(1), 17-26. doi:10.1375/ajgc.15.1.17

Slee, P. T., \& Rigby, K. (1993). The relationship of Eysenck's personality factors and self-esteem to bully-victim behaviour in Australian schoolboys. Personality and Individual Differences, 14(2), 371-377.

Smokowski, P. R., Kopsz, K. H. (2005). Bullying in school: An overview of types, effects, family characteristics, and intervention strategies. Children Schools, 27(2), 101-110. doi: $10.1093 / \mathrm{cs} / 27.2 .101$

Thomaes, S., Bushman, B. J., Stegges, H., Olthof, T. (2008). Trumping shame by blasts of noise: narcissism, selfesteem, shame, and aggression in young adolescents.
Child Development, 79(6), 1792-1801. doi: 10.1111/j.1467-8624.2008.01226.x

Tritt, C., \& Duncan, R. (1997). Research: The relationship between childhood bullying and young adult self-esteem and loneliness. The Journal of Humanistic Education and Development, 36(1), 35-44. doi:10.1002/j.21644683.1997.tb00426.x

Ttofi, M. M., Farrington, D. P., \& Losel, F. (2012). School bullying as a predictor of violence later in life: A systematic review and meta-analysis of prospective longitudinal studies. Aggression and Violent Behaviour, 17(5), 405-418. doi:10.1016/j.avb.2012.05.002

Volk, A., Camilleri, J. A., Dane, A. V., \& Marini, Z. A. (2012). Is adolescent bullying and evolutionary adaptation? Aggressive Behaviour, 38, 222-238.

von Manen, M. (1990) Researching lived experience: Human science for an action sensitive pedagogy. State University of New York Press, New York.

Walz, G. \& Bleuer, J. (1992). Student self-esteem: A vital element of school success. ERIC Counseling and Personnel Services, Inc., Greensboro: N.C.

Wan Ismail, S. W., Jaafar, N. R. N., Sidi, H., Midin, M., \& Shah, S. A. (2014). Why do young adolescents bully? Experience in Malaysian schools. Comprehensive Psychiatry, 55, S114-S120.

Wang, J., Iannotti, R. J., \& Nansel, T. R. (2009). School bullying among adolescents in the United States: Physical, verbal, relational, and cyber. Journal of Adolescent Health, 45(4), 368-375. doi:10.1016/j.jadohealth.2009.03.021

Weiten, W., Hammer, E.Y., \& Dunn, D.S. (2012). Psychology and contemporary life human adjustment. United State: Wadsworth Cengage Learning.

Yang, S. J., Kim, J. M., Kim, S. W., Shin, I. S., \& Yoon, J. S. (2006). Bullying and victimization behaviours in boys and girls at South Korean primary schools. Journal of the American Academy of Child \& Adolescent Psychiatry, 45(1), 69-77. doi:10.1097/01.chi.0000186401.05465 